\title{
EXPANDING AN UNDERSTANDING OF URBAN RESILIENCE IN THE REALM OF ADAPTATION PLANNING
}

Natalie ROSALES, CONACYT-El Colegio Mexiquense; Mexico

\begin{abstract}
As cities have become more central to development, resilience, risk assessment and prevention instruments have gained greater importance in urban planning considerations. By using the case study of Mexico City's Climate Action Programme, this piece of work contests the way in which resilience has been embedded in urban adaptation planning. Grounded on a planning evaluation based approach to analyze on which methodologies, tools, and frameworks have been used, and which key actions and strategic lines to building resilient cities are contemplated, this descriptive research incorporates urban-regional metabolism dynamics and environmental data such as carrying capacity, into Mexico city climate change scenarios and vulnerability analysis matrix. By doing so, the article introduces new ideas that can: i) move from risk management to uncertainty oriented planning; ii) understand vulnerability in the context of equitable sustainable development, while highlights the opportunities transformative resilience offers to enable transformations towards sustainable urban futures
\end{abstract}

\section{Keywords}

Transformative resilience, urban planning, urban resilience, sustainability indicators

\section{Resilience as a new framework for planning the cities}

In the face of such challenges as growing inequalities, natural resources depletion, peak oil, climate variability, extreme weather events and global economic challenges, the arrival of resilience as a concept within the social sciences to inform political rhetoric, as well as a heuristic and operational tool, has positioned it as a new paradigm and a banner (Lampis, 2015).

The concept has crossed disciplinary discussions becoming a thinking approach, which investigates how interacting systems of people and nature can best be managed in the face of disturbances, surprises, and uncertainty (Biggs et al., 2015). It has also been progressively embedded into policy-oriented discussions, mainly focused on climate and global environmental change (Lampis, 2015). In this way, more and more we hear about resilience as an applicable concept to prevention strategies, community empowerment, collaborative initiatives, economic recovery, urban planning strategies, and so on. In fact, the term has been a great catalyst for community management and adaptation planning focused on 
identifying specific measures and processes that can address the uncertainties of climate change through action and implementation. Thus we find that at the local level, an increasing movement to build resilient communities has grown over time aiming to "anticipate[s] problems, opportunities, and potentials for surprises; reduce[s] vulnerabilities related to development paths, socioeconomic conditions, and sensitivities to possible threats; respond[s] effectively, fairly, and legitimately in the event of an emergency; and recover[s] rapidly, better, safer, and fairer" (Hearn, 2008).

Following these tendencies the concept has arrived in the urban arena and the efforts to build resilient cities have increased, generating new perspectives and urban planning frameworks to tackle the enormously complex interactions between different (non-scalar) components of socioecological systems, which include governance networks, economic systems, resource flows, social dynamics and the structure of the built environment (Resilience Alliance, 2007). Among these new approaches, stands out the following three: disaster risk reduction (DRR); social vulnerability; and urban political ecology.

\subsection{Resilience and climate change adaptation and disaster risk reduction (DRR) approach}

Recent discussions on sustainability connect global warming and climate change, and their association with resilience. Becoming a widely debated issue in urban sustainability and risk management literature. The planning resilience approach rooted in risk and uncertainty argues that change will occur, and as unexpected shocks are not able to prediction. Therefore, cities must strengthen their capacity to handle and deal with external threats such as natural disasters (hurricanes, floods, and earthquakes), the depletion of natural resources (oil, water) and shocks (Abhas, et al., 2012).

In this regard, the notions of building resilience refer to the ability of human settlements to withstand and to recover quickly from any plausible hazards. However, also from an economic standpoint, it stresses the importance of recovering from crises, not only by reducing risks and damages from disasters (i.e., loss of lives and assets), but also strengthening the ability to quickly bounce back to a "stable state" (UN HABITAT, 2016).

This vulnerability/resilience paradigm which calls on building resilient and intelligent urban environments, who are able to "anticipate" future shocks, has been driven by international institutions like the World Bank, UN-Habitat, the European Commission, ICLEI, and has mostly replaced a hazards approach in the social sciences (ICLEI, 2012).

As such, there are different initiatives focused on developing city stakeholder's capacity to address the challenges, uncertainty, and unpredictability of all types of change and disturbance. Including natural hazards, such as the Resilient Cities Project from the OECD; the United Nations International Strategy for Disaster Risk Reduction (UNISDR) launched its 2010-11; the Worldwide Disaster Reduction Campaign explicitly including the issue of 'resilient cities'; ICLEl's Resilient Cities initiatives; UN-Habitat City Resilience Profiling Programme; Rockefeller Foundation's 100 Resilient Cities project, just to name a few.

Nevertheless, even when, much of the literature and practices focus on this approach, resulting in disaster reduction and a better understanding of hazard, there is increasing recognition that a more complex part of the equation lies in the way in which societies are organized (Mitchell, 1999). 


\subsection{Resilience and the critical perspectives approach}

The social vulnerability approach

From a critical theoretical framework, there is an essential body of knowledge that investigates and evaluates the social, institutional, and policy roots of urban ecosystem resilience to understand the nonlinear relationships and interacting systems (Campanella, 2006). These studies have focused on how different urban ecosystems can adapt, adjust, renew and transform in response to trauma, national economic and demographic challenges, and global climate change, highlighting an important issue: resilience is the counterpart of vulnerability (Campanella, 2006)

Under this point of view, the social vulnerability approach emphasizes that there are specific social, political and economic processes and structures that lead to vulnerable conditions. So, risk varies not just according to the hazardous agent, as it is distributed unequally among the impacted population and communities. Therefore, advancing resilient actions in anticipation of risk, in reaction to impacts, or recovery from the effects, requires four factors: (1) knowledge of the hazard; (2) accurate perception of the risk; (3) understanding available alternatives; and (4) resources and flexibility. These factors most of the time are out of control of the population as they depend on more significant economic and social forces (Wilbanks, 2008).

In this regard, this social vulnerability approach helps to explain how communities that operate as groups with a sense of collective cohesion and identity, deal with adversity and stress and gain or lose functioning and strength as a result of trauma and disaster (Campanella, 2006).

The political urban ecology approach

Researchers supported by a critical school of thought, remind us that "cities are fundamentally natural, as human and no human residents compose their population, formed from earth material, and supported by ecological processes which are always due to politicization. Whether in the flow of water through the city, the uneven distribution of trees in its landscapes, or the environmental hazards imposed upon its citizens" (Robins, 2012). So, two concepts that have entered urban political ecology in its encounter with resilience approaches are the metaphor of urban metabolism and the notions of environmental justice.

Urban metabolism can quantify not only the dependencies cities have on external resources and how this relation can affect their adaptive capacity. Also, aiding to understand the way in which powerful actors and interests bend and funnel natural materials and forces to increase rents, develop properties, fuel growth, empowering or disempowering communities.

On the other hand, the concept of environmental justice points out that exposure risks are significant and unquestionably associated with historically dis-enfranchised groups (Cutter, 1995). This idea predicated on the well-known fact that disempowered communities (especially racial minority groups and the urban poor) have been located in and around technological and natural hazards ( lead smelters, garbage incinerators, or power plants).

These two epistemological assumptions argue that understanding how urbanization operates in metabolizing nature and in the creation and distribution of risks, vulnerabilities, and opportunities among urban dwellers, are imperative for addressing resilience at the 
urban scale. So, in order to build resilient communities there is a need for a deeper understanding of public responses to these challenges, and how planning can support synergistic relationships between resilience and environmental (The Bartlett Development Planning Unit, 2016).

Based on these different approaches, the debate about resilience has become central to urban sustainability, so risk assessment and prevention instruments have gained greater importance into urban planning considerations. In particular, the adaptation and disaster risk reduction (DRR) approach has been introduced as a useful framework to tackle the environmental, social and economic risks posed by climate change in cities.

Nevertheless, even when this use of the concept, represents an advance in contemporary planning frameworks, the focus on urban risk management, which has dominated the incorporation of resilience in planning practice, tend to restricts assessment and strategies to anticipate short-term disturbances, such as hazard or disaster recovery; while leaves aside vulnerability, environmental justice, and the capacity of urban systems to adapt, in the wider context of urban sustainable transitions.

In order to illustrate this, the following section will then focus on urban resilience strategies and approaches implemented in Mexico City's planning instruments.

The aim is to chart the contours of a critical assessment, exploring the use of the concept, the shortcomings of the principles adopted and how can we move forward to use this heuristic tool as a part of a comprehensive urban sustainability strategy.

This analysis is grounded on a planning evaluation based approach, and it is divided into three parts: i) a study on which evaluation frameworks, methodologies, tools and key and strategic lines to building cities resilience are contemplated; ii) a quantitative and qualitative analysis that incorporates urban-regional metabolism dynamics and environmental data such as carrying capacity, into the climate change scenarios and vulnerability analysis matrix, in an attempt to forecast future scenarios and define some priorities to increase socio-ecological sustainability and resilience; and iii) a proposal to move from risk management to uncertainty oriented planning.

\section{Planning framework for building urban resilience in Mexico City: The Climate Action Programme}

Mexico City experienced a fast population growth leading the city spread to vast geographic expansion. This rapid change imposed pressures on urban eco-systems by creating new demands for land and more ecological services; increasing demand for urban infrastructure and services. The tensions due to the rapid growth and undersupply turn into water scarcity, traffic congestion, energy consumption, air pollution, and the appropriation of green areas for development.

At the same time, socio-economic and institutional factors have driven poor people -with a relatively little latitude of choice for house construction- into building houses on steep hillsides, making ecosystems more vulnerable to degradation.

Therefore, the issue of various environmental contingencies, by the hand of the recent intensification of meteorological events due to climate change, has increased cities 
vulnerability, giving centrality to issues such as sustainability, and more recently, urban resilience.

In the last years, Mexico City, as an international actor, has positioned itself in the national and global contexts as one of the cities which is driving resilience projects, due to the assumed leadership on the climate change agenda promoted since the COP 16 held in Cancun. So, the debate around resilience concerning climate change has become one of the new narratives permeating the City's different legal planning instruments.

Also, the city has joined the program 100 Resilient Cities (100RC) from the Rockefeller Foundation and has received funding by $\$ 200$ million to boost various programs and resilience strategies since 2015 . Additionally, the government has allocated $10 \%$ of its budget, representing nearly 17,000 million pesos to boost resilience strategies. This initiative comprises four vulnerabilities areas and stress caused by disasters. i) Financing innovative technology infrastructure; ii) land use; iii) social and community resilience (Quintero, 2016).

Under this context, the main effort to incorporate resilience into planning instruments, identified is the Climate Change Action Programme 2014-2020.

\subsection{Mexico City Climate Action Programme and the notions of urban resilience}

Mexico City's Climate Action Program (PACCM, in Spanish) for 2014-2020 is a planning tool that integrates, coordinates and promotes actions to reduce the environmental, social and economic risks posed by climate change while simultaneously promoting the welfare of the city's population through strategies contained in the Local Climate Action Strategy (ELAC, in Spanish).

Regarding adaptation, the PACCM aims to increase the city's resiliency as well as the population's adaptation capacities, particularly for the 5.6 million people most vulnerable to extreme weather events, such as flooding. To achieve these goals, the PACCM includes specific actions for each of the strategic priorities that make up the Climate Action Local Strategy shown in Figure 1. These priorities seek to maximize synergies between adaptation and mitigation, in order to increase the cost-effectiveness of implemented actions to make them more attractive to potential funding bodies and other decision-making entities.

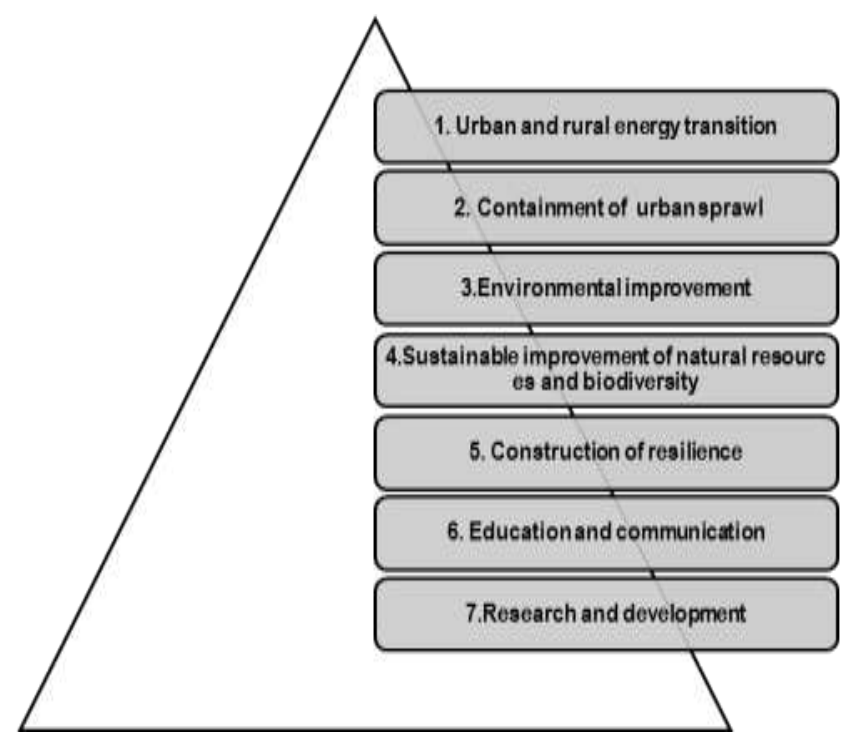


Figure 1. PACCM strategic priorities. Source: Authors elaboration based on Climate change Programme

As can be seen, building resilience to face the adversities of the process of mitigating and adapting to climate change is a particular objective and consequently one of the main components of the Climate Action Programme.

The term resilience is conceptualized as "the ability of citizens to absorb shocks and reorganize while undergoing climate change through decentralization of activities, the diversity of economic sources, decoupling between economic development and emissions $\mathrm{CIS}$, the integration of the city with natural ecosystems, social cohesion and redundancy" (Gobierno de la Ciudad de México, 2014).

Accordingly, with this definition, the programme sets four attributes of an urban system to be resilient (Molina et al., 2013):

- Decentralization. Which refers to spatial dispersion of the critical activities in the city, to allow that in case of a disturbance in an area of the territory, the rest of the city can continue running smoothly.

- Diversity. Economic growth should decouple GHG emissions and integrate environmental concerns. Urban centers should be more efficient and less polluting.

- Flexibility. Ability to face disasters. It may be an administrative type, in infrastructure, economic activity.

- Redundancy. It refers to the duplication of the key and essential city services. The city must continue operating by using alternative networks, before collapsing.

Build upon this theoretical framework (resilience in reference to climate change adaptation), the plan departs from a diagnosis of the current situation of the city, focusing on two main aspects; exposure to multiple risks (extreme rainfall resulting in floods or landslides, droughts, heat waves) and poverty and inequality that contributes to high concentration of vulnerability in marginalized groups. So, vulnerability, as a key concept is a compound consequence of the fragility of the urban systems, the capacity of internal agents - including poverty, social marginalization- and other factors such as exposure to the impacts of climate change.

In this regard, by using indicators of exposure, sensitivity and adaptive capacities, the action programme indicates that the periphery is more vulnerable to climate change. Iztapalapa, Cuajimalpa, Xochimilco and Alvaro Obregon have an outstanding range of medium-high to very high; in contrast to the central areas which have low levels of vulnerability.

Strategies and recommendation for building resilience are placed at the broader context of adaptation to address the specific vulnerabilities to climate change which focuses on five issues:

- Urban and rural energy transition:

Energy efficiency

Renewable energy

- Containment of urban sprawl:

Urban planning instruments 
Intra-urban green spaces

Infrastructure mobility and transport

- Environmental enhancement:

Reduction of emissions

Integrated waste management

Integrated management of water resources

- Management of natural resources and biodiversity conservation:

Native species and wildlife

Soil conservation

- Building resilience of the city:

Prevention and mitigation

In this line, the action programme promotes prevention and risk mitigation focusing on creating an environmental and economically active population despite destabilizing events, such as natural disasters caused by extreme behaviour on the elements of weather, environmental degradation, and economic and social crisis. Therefore adaptive mechanisms for building urban resilience are associated with the vulnerability of the population, damage to infrastructure (road, hydraulic, electric) and public health. Also, are associated with the improvement of the administrative, organizational capacity to move from prevention to mitigation of risk.

In this regard, key actions to build resilience refer to designing:

Up-to-date Hazard and Risk Atlas

Prevention Program (hydro-meteorological hazards)

The study, evaluation, and relocation of human settlements situated in risk areas

Early warning system to monitor and forecast hydro-meteorological condition of the metropolitan area

A preventive measure system in case of extreme weather events

Training and dissemination of prevention strategies related to climate change, to strategic sectors

Monitoring and prevention vector-borne integrating information

Prevention diseases program

An Environmental Fund for Climate Change

The strategy also explicitly recognizes the fact that building urban resilience to climate change cannot be achieved through 'one-time' activity or 'one-off' projects. Integration of multiple interventions at different scales and across different sectors is a must over time. Also, it emphasizes the role of external actors in catalysing and enabling responses, working with and through internal agents, and influencing where investment in changes to urban management is required. 
For instance, it promotes an integrated approach which incorporates three topics: Urban planning, mobility, and environmental enhancement. The programme also remarks that mitigation actions should demonstrate co-benefits in the adaptation actions, and vice versa, seeking a positive impact on environmental and social development.

\subsection{Analysis of the adaptation planning framework}

Mexico City's adaptation planning framework helps illustrate how resilience undertakes within the aims and practices of contemporary planning instruments; what are the advantages and shortcomings of the principles adopted, and how can we rethink the concept of resilience within this planning frameworks to guide sustainability transitions. Table 1 synthesizes methodologies, tools, and evaluation frameworks.

\begin{tabular}{|c|c|}
\hline ISSUE & DESCRIPTION \\
\hline $\begin{array}{l}\text { Urban } \\
\text { resilience } \\
\text { approach }\end{array}$ & $\begin{array}{l}\text { Building resilience is at the broader context of the adaptation strategy } \\
\text { that addresses the specific vulnerabilities to climate change. } \\
\text { The planning instrument considers that a city can become more resilient } \\
\text { concerning adapting to and ensuring the restoration of basic services, as } \\
\text { well as social, institutional and economic activities. } \\
\text { Concepts related: } \\
\text { The framework focuses on the relationship between vulnerability and } \\
\text { climate change. It considers exposure to risk, sensitivity, adaptive } \\
\text { capacities, and internal agents. } \\
\text { Vulnerability understood as a compound consequence of the fragility of } \\
\text { the urban systems, the capacity of internal agents - including poverty, } \\
\text { social marginalization, and other factors such as exposure to the impacts } \\
\text { of climate change. }\end{array}$ \\
\hline $\begin{array}{l}\text { Methodologies } \\
\text { and } \\
\text { evaluation } \\
\text { tools }\end{array}$ & $\begin{array}{l}\text { Methodology } \\
\text { The planning instrument combines investigation, data, and analysis to } \\
\text { diagnose vulnerability. } \\
\text { Overall the framework provides a robust analytical foundation for } \\
\text { understanding vulnerability to climate change which then informs the } \\
\text { identification and implementation of mitigation and adaptation actions, } \\
\text { seeking synergies and co-benefits. } \\
\text { Methods for analysis consider: } \\
\text { Climate change scenarios } \\
\text { Greenhouse compounds inventory emissions, which incorporates black } \\
\text { carbon and fluorocarbons. } \\
\text { A planning evaluation system which makes the plan (measurable, } \\
\text { reportable and verifiable) every action has specific monitoring and } \\
\text { impact indicators. } \\
\text { It has an online tracking platform which provides information for }\end{array}$ \\
\hline
\end{tabular}


decision-making, in a timely and effective manner.

Indicators to measure vulnerability include:

exposure to risk, sensitivity, adaptive capacities

Table 1. Analytical table

Based on this, it is possible to determine that this planning instrument combines investigation and data collection providing a robust analytical foundation for understanding vulnerability to climate change. In this manner, can be argue that the action plan in operational terms, is useful for understanding resilience in the broader framework of climate change and urban risk management, as it helps to identify:

- What are the hazards? What are the impacts?

- Who (which agent) or what (sector,) is going to be affected by which aspects of climate change?

- Specific sources of vulnerability and capacities associated with specific groups of agents and systems concerning specific change processes

- What needs to be done to address the impacts of climate change?

Still, as argued before, the focus on this climate adaptation planning and urban risk assessment approach, leaves out important issues that should be taken into consideration to forecast future scenarios and define some priorities to increase socioecological sustainability and resilience. First, an important matter related to resilience is concerning the degree to which cities can tolerate alteration is the level of exhaustion of natural resources. This matter deserves a high priority, as it represents a future shock that can affect environmental vulnerability entering the city in a condition of hysteresis. This concept relates a process of degradation which is not reversible by merely eliminating disturbances and may lead to new states (Westoby et al., 1998).

Cities as complex systems have multiples states, and the path back from a disturbance is often different than the path forward, some impacts may be considered irreversible, and may lead to new states. So, resilience does not always require that the system will return to its previous state or equilibrium but instead can adapt and transform into a new state that will allow it to survive further and future change (Folke, C. et al., 2010).

In this sense, Arefi (2011) argues that cities share these resilience abilities and are the subject of a various range of changes (Arefi, 2011).

Therefore, it is essential to use, as analytical tools, ecological concepts that will present a clear idea of the critical attributes of the urban system: adaptive capacity, self-organization, and transformability (Eraydin, 2013). This includes, natural resources availability, carrying capacity, ecological balance, environmental assessment scenarios, (Rosales, 2017). In addition, a resilient strategy should not be based only on mitigating and adapting to climate change, it should incorporate how to carry out incremental adjustments to move the city towards a circular metabolism and sustainable urban futures. 
Second, resilience is, a powerful concept as it encompasses a better understanding of the complex interactions between the different components of socioecological systems including resource flows (production, supply and consumption chains; built environment (ecosystem services in urban landscapes); social dynamics (human capital and inequity); and governance networks (institutional structures and organization); their strengths and weakness. Therefore an underlying aspect interwove among these components is the notion of risk and vulnerability, which is not only related to exposure, sensitivity and adaptive capacities of a population but also with the specific social, ecological, political and economic processes that lead into vulnerable conditions (Campanella, 2006).

These multifactorial conditions have a particular interest in assessing resilience because vulnerability can be shifted onto disempowered populations (such as urban peripheries, and rural and peri-urban environments), or gained at the expense of adjacent cities (regional or national) or smaller (district level) systems (Chelleri \& Olazabal, 2012).

Understanding the way how cities grow and metabolizes nature through infrastructure, not only reinforces an unequal distribution within regions, urban-rural domains, but also can lead to the empowerment of al-ready powerful and advantaged groups, while disempowers marginalized individuals and groups (Heynen, N., M, Kaika., \& Swyngedouw E., 2006) can serve as a starting reflection point to determine opportunities and threats of urban systems to become more resilient and sustainable.

Therefore, indicators that better reflect the complexities of urban flows in relation to resilience, such as the metabolic flows of cities and regions (Rosales, 2018), which are a key component to understand the vulnerability matrix in the wider context of a sustainable development, should be incorporated.

In an attempt to illustrate how these oversights of the climate adaptation planning can be overcome, and properly carry out a resilience assessment, the next section will incorporate urban metabolism and sustainability environmental indicators into the analysis.

\subsection{An assessment framework for the use of resilience in urban planning}

Understanding urban-regional metabolism dynamics for climate adaptation and mitigation scenarios

In 2012, Mexico City consumed approximately 14 million MWh, which represents $7 \%$ of annual national energy consumption. The city's location is in a basin, where there are not intensive processes of electricity generation, oil activities or heavy manufacturing. So, only $20 \%$ of electricity is generated within the area, while the rest comes from the National Interconnected System (SENER, 2009). These issues imply that the city needs to design a strategy to be prepared to possible sustainability crises, such as energy shortages, pointing out as well, the imperative to move the city towards alternative (back-up) and diverse energy supply sources.

In the same year, the city produced 31.842 million tons $\mathrm{CO} 2$ equivalents emissions which, $80 \%$ derives from energy consumption in the form of fossil fuels and electricity, mainly from the transport sector while solid waste is the second factor which contributes to emissions generation (Molina et al., 2013).

Modelling scenarios estimate that in 2020 CO2e will increase to 34.5 million tons, and by 2025 about 37 million tons of CO2e, while the PACCM 2014-2020 will contribute to the 
reduction of 8 million tons of CO2e and 2 million tons (Gobierno de la Ciudad de México, 2014).

These facts raise questions that both policymakers and planners need to consider. For example, material flows such as solid waste, which is also a significant contributor to emissions, would imply that building strategies for a resilient city need to set goals for dematerialization (consumption of fewer materials) and how to carry out incremental adjustments to move the city towards a circular metabolism.

In regard to disturbances, the scenarios methodology to project and predict the future risk associated with the climate change impacts, shows that according to the climate evolution patterns for Mexico City in the short (2030) and medium term (2050) possible future shocks could come from: a) The agricultural cycles by changes in the seasonality of temperature and rain; b ) The creation of new habitats for the development of pest or disease vectors; c) Changes in biological diversity biomes and; $d$ ) Shortage of water resources.

Regarding to natural resources, even if water scarcity has always been a red spot for sustainability in Mexico City, water shortage factor of risk is not considered, in the current model as an environmental vulnerability which could drive changes in the system at multiple scales (for instance, an ecological region). So, if additionally to climate change scenarios we incorporate environmental indicators to understand the urban -regional metabolism dynamics, we can have a broader picture of imbalances in the urban system to forecast possible short and long-term disturbances that will help to adjust in the face uncertainty, designing prevention and adaptation strategies to manage this scenario.

For instance, water stress indicators can reflect the total volume of water extracted concerning the average natural water availability. In the case of Mexico City, water stress in the region is $120 \%$ (SEMARNAT, 2010).

Water supply has increasingly come from farther away. So the transfer of water extends about 130 kilometers. In addition to this long distance, Mexico City location in a valley implies that water must be pumped a thousand meters, equivalent to the burning of 3.4 million barrels of fuel per year (Tudela, 1991).

This information, therefore, not only confirms the strong dependency on external sources of water supply but also raises questions about the marked vulnerability to water availability, revealing how this relates to the contribution to green gas emissions; and the levels of environmental impact of the city.

The notions of resilience is related to the capacity to cope with disturbances, alternative stable states of complex systems and a dynamic balance. From this perspective, resource availability of the city to supply urban population demands, and ecological balance are also, two important factors to consider.

Bearing in mind that the predicted Biocapacity of the Earth estimation is 01.8 global hectares per capita (World Watch Institute, 2007), and the following results from the quantification of Mexico City carrying capacity $(166,031 \mathrm{Ha})$. 


\begin{tabular}{|c|c|}
\hline LAND USE & Has \\
\hline $\begin{array}{l}\text { Fossil } \\
\text { absorption has been } \\
\text { related to forest } \\
\text { surfaces (172.22 } \mathrm{km} 2) \\
\text { and reforested areas }(4 \\
\mathrm{km}) .\end{array}$ & 17,622 \\
\hline 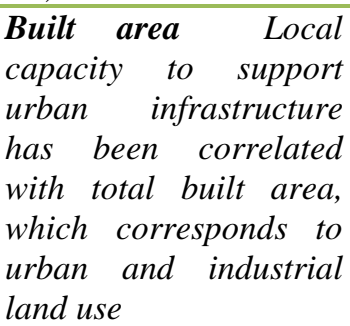 & 59,192 \\
\hline $\begin{array}{lr}\text { Cultivable area } & \text { for } \\
\text { food production } & \text { is } \\
\text { related to } & \text { the } \\
\text { agricultural area } & \end{array}$ & 37,184 \\
\hline $\begin{array}{l}\text { Pastures are associated } \\
\text { with grassland, desert } \\
\text { scrub and secondary } \\
\text { vegetation. }\end{array}$ & 34,527 \\
\hline Forest & 17,222 \\
\hline $\begin{array}{l}\text { Water and the category } \\
\text { sea (water) is related to } \\
\text { water bodies }\end{array}$ & 284 \\
\hline TOTAL & $\begin{array}{l}166,03 \\
1\end{array}$ \\
\hline
\end{tabular}

Table 2 Local Source: Authors elaboration based on (INEGI, 2010)

Mexico City to be ecologically sustainable would need about 15,906,631 ha. Ergo, the City has an ecological deficit of $15,740,600$ ha because its population surpasses its carrying capacity in $90 \%$, entering in a condition known as ecological overshoot.

These facts reinforce the importance to consider the availability of resources and urban metabolism dynamics, in order to assess its adaptive capacity, self-organization, and transformability. Mostly those related to water bodies to supply the demand, and food selfsufficiency regarding the low production due to the limited agricultural amount of space available. In particular, because climate change can exacerbate impacts affecting agriculture systems and water shortage. So, integrating food security and urban water cycle as analytical elements into urban planning should be established as a critical aspect of any comprehensive urban resilience strategy.

Understanding the vulnerability of urban systems in the context of an equitable and sustainable development.

While it is true that the city has a water shortage, due to the levels of exhaustion of the resource, and the fact that in the Metropolitan Area of Mexico water supply systems have been operating beyond their limits. This situation depends on the specific social-economic condition of the area in such way that unequal access to resources and disparities in the provision of infrastructure affects mostly the population in the southeast areas (Iztapalapa, Tláhuac, and Xochimilco), which have the lowest income levels. 
Accordingly, to the Climate Change Action Program, the degree of exposure to the risk in the city varies from low to medium where the vulnerable population localizes on the south (in the delegations Tlalpan, Magdalena Contreras, Álvaro Obregón and Cuajimalpa). Mainly, characterized by irregular human settlements patterns, where the steep slope is very prone to washouts by the presence of water erosion.

\begin{tabular}{|l|}
\hline Vulnerability \\
\hline Critical \\
\hline Iztapalapa, Alvaro Obregon, Tlalpan, Tlahuac, Xochimilco y Milpa Alta \\
\hline Medium \\
\hline Azcapotzalco, Coyoacan, Cuajimalpa,Gustavo A. Madero, Iztacalco,La Magdalena Contreras y \\
\hline Above average \\
\hline Benito Juarez, Cuauhtemoc y Miguel Hidalgo \\
\hline
\end{tabular}

Table 3 Degree of exposure to risk of the population in the city. Source: (Gobierno de la Ciudad de México, 2014)

Following the assessment model, when adding the effects of climate change such as 1) Growth in water demand. 2) Increased degradation in catchment areas. 3) Reduced water quality and recharge, among others, it is possible to foresee the way in which some parts of the city will increase their vulnerability.

As the table 2 shows water availability in the different municipalities of the city, already present critical levels of consumption in those settlements with the lowest welfare conditions, while higher income sectors consume over $80 \%$ of the water provision available.

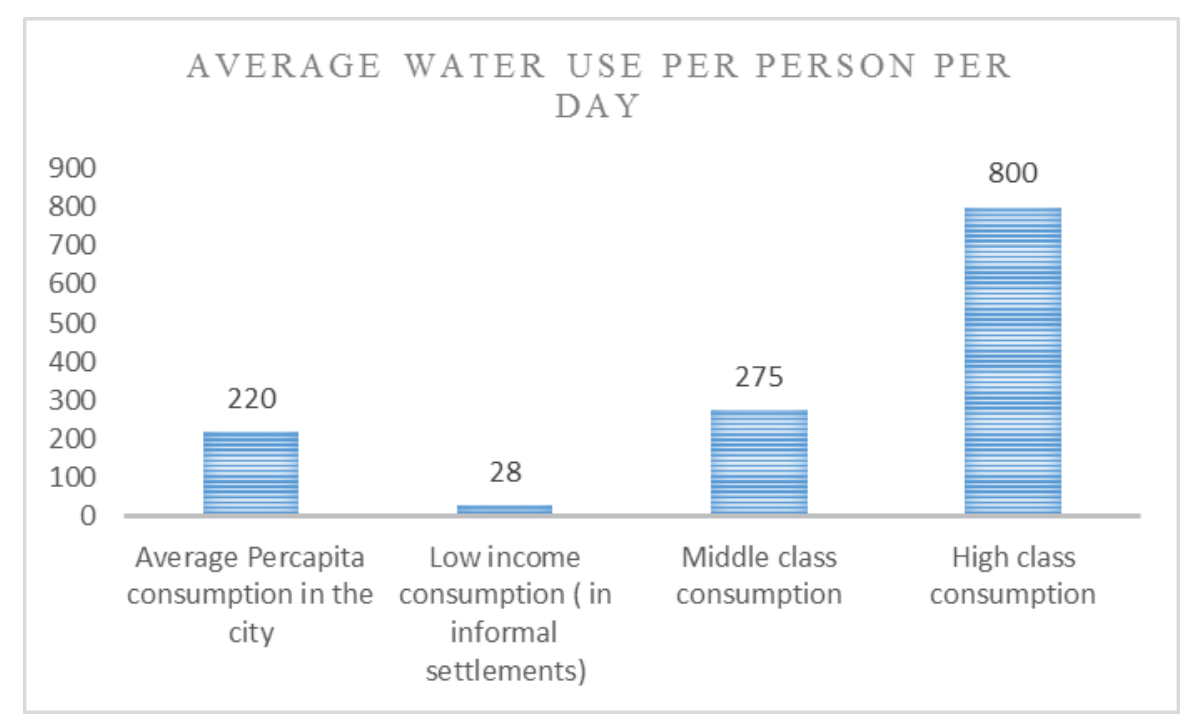


Figure 2. Water consumption inequities. Source: authors elaboration based on (López, 2006)

These contradictions that extend beyond the city limits, due to the way city metabolizes nature, not only reinforce an unequal distribution of metabolic flows within but also generates vulnerability in nearby areas.

For instance, water scarcity impacts ecological systems at a bioregional level. The average production of wastewater in the sub-region in 2012, amounted to 1.66522 million m3. From this, only $78 \%$ of channels treatment plants. The water waste re-usage has come up to only $4 \%$. Then, $22 \%$ of the negative externalities of Mexico City are transferred to other regions, displacing environmental risk and vulnerability to rural areas such as the Mezquital Valley (Rosales, 2013).

This better understanding of why people and places are affected differently, and how the growing inequalities in the cities constrain or trigger this conditions of risk and vulnerability in the urban space, and among regions point out critical issues concerning environmental justice at different scales, that should be also incorporated into planning.

Understanding resilience in a wider context. Adaptive capacity, self-organization, and transformability

One of the main aspects that underlies the conceptualization of resilience in the case study presented, is related to the capacity to cope with disturbances and return to a stable state. Nevertheless, as Timon McPhearson argues “...given the often enormous inequities in our cities, we need to be thinking about resilient of what, to what, and perhaps especially, for whom?"... (McPhearson, 2014).

As planner, and inhabitant of Mexico city, I can argue that the city has become a resilient entity, while remains highly vulnerable to factors such as social inequality, uncontrolled growth of urban sprawl, informal settlements, natural resources scarcity, and ecological systems degradation.

The poor and vulnerable are continually being resilient, under the disturbances and changes due to socio environmental dynamics, as that is how they live their lives. In this way, the city has achieved a precarious balance that maintains the urban system "functionality" despite its environmental crisis and its ecological overshoot.

So, one of the questions which raises this case study, is do we really want to maintain this fragile equilibrium and the status quo, or what we need is a new state, and a city resilience transition strategy acting in the interests of the poor and vulnerable and highly degraded environmental systems.

A comprehensive urban redevelopment strategy changing internal and external processes and socio environmental dynamics can provide the means to shift the growth trajectory of the city towards a more equitable, environmentally sound and therefore sustainable direction (Agyeman, 2013). But, how can we move towards this direction?

\section{Rethinking adaptation planning}

The theory of resilience can support the conceptualization and development of tools, to help understanding the city as a complex socio-ecosystem and manage urban sustainability 
transitions, by providing a long-term perspective based on the three key concepts: learning, adaptation, and transformation (Walker \& Salt, 2006).

This broader perspective implies going beyond the use of resilience and disaster risk reduction assessment and climate change adaptation.

This latter interpretation based on resilience as a dynamic process involving recover from disturbances, but also to carry-out incremental adjustments (adaptations) and; exploring and expanding the capacity to innovate and transform (Holling, 1973), can then, become the frog leap to move planning adaptation framework towards a more comprehensive and integrated approach to face sustainable transformations.

This process, according to Olsson, requires: (1) preparing for change, (2) navigating the transition, and (3) building the resilience of the new trajectory of development (Olsson et al., 2006).

The question then is, how can this transformative notions of resilience be introduced in existing adaptive planning? This article argues that the shift can be done by a) moving from risk management to uncertainty oriented planning, b) Understanding vulnerability in the context of an equitable, sustainable development; and as a result, c) embedding resilience as a heuristic device in planning models.

\subsection{Moving from risk management and climate adaptive planning towards urban resilient transition: uncertainty oriented planning}

Moving from vulnerability risk analysis to urban resilience transitions call for understanding urban- regional metabolism dynamics; the degree to which cities can tolerate alteration and perturbances before reorganizing; dealing with uncertainties; conceptualizing what transformations are needed; setting targets and ways of transiting towards sustainability processes and scenarios, and new rationality in planning.

This focus on change and uncertainty, challenge mainstream planning models, based on the two dominating paradigms, rational, comprehensive, and communicative planning, which have dominated the practice. First, because often look at past trends and known problems instead of dealing with uncertainties (Jabareen, 2012). Secondly, because adaptive planning frameworks, which emphasize maintaining the resilience status of the city, do not appear to be contributing sufficiently to the achievement of resilience at the broader context of the sustainable paradigm.

Thus, resilience planning should integrate risk management, adaptive planning in the broader frame of planning for urban sustainability.

As illustrated with Mexico City case study, this integration requires a systemic view for understanding the different processes or components and the way how they interact with each other. For instance, the dependency that cities have on external resources such as food, water, products and energy; and the adaptive capacity of the city to respond to threats related to resource crises or climate/natural disaster events.

These should be complemented by a science policy interaction that can help to design appropriate strategies for a resilience city transition, such as slow exploitation, goals for dematerialization (consumption of fewer materials) and decarbonization (consumption of less carbon). 


\section{Concluding remarks}

Urban resilience transition demands new strategic approaches to planning frameworks, methodologies and evaluation tools. This challenges not only conventional planning models but also states the importance of evaluating the way resilience has been revisited and embedded in contemporary planning. Therefore, it is essential to bring our analytical gaze to the theory and planning practices which attempt to target an urban resilience transition, comprehensively, to promote more suitable and effective proposals towards the construction of sustainable cities.

The analysis of Mexico City Climate Change Programme helps illustrate the incorporation of resilience within the aims and practices of contemporary planning instruments. Also, what the advantages and shortcomings of the conceptual approaches adopted and the proposed strategies are.

In this regard, one of the critical points of the discussion of this article is that evidently, resilience has been, mainly, incorporated in instruments based on DPRS approach resulting on climate adaptation planning.

Even though the above approach is an advance into integrating economic, environmental and social aspects with mitigation and adaptation into planning, there has been a narrow use of the resilience concept.

Urban resilience transitions necessitate going beyond identifying and predicting the impacts of climate change spatially to overcome disaster situations, vulnerability or possible impacts.

Resilience as a heuristic device has the potential to forward sustainable transformations, instead of preserving the status quo of the stable condition on which the city and their inhabitants have found an equilibrium grounded on ecological overshoot, poverty, sprawl, inequality, and threats to human and ecosystem health.

Embedding transformative resilience into planning frameworks offers excellent possibilities to understand the interactions among metabolic flows, the environment, social dynamics and governance networks. As well as the conceptualization of strategies to manage urban sustainability transitions which encompasses: exploring the capacity of urban systems to cope with short-term disturbances and long-term changes; stretch resources to meet the increased demand for shelter, water, secure food security and energy in scenarios of scarcity; adapting to new scenarios; and enable transition of new trajectories of change.

In sum, the value of incorporating resilience into planning should lie on the way this heuristic concept can help us to face transformations towards social, economic and ecological sustainable systems.

\section{References}

Abhas K. Jha, Todd W. Miner, and Zuzana Stanton-Geddes. (Eds). (2013). Buinding urban resilience: Principles, tools and parctice. Washington: The World Bank. Y en texto se tendría que citar (Abhas, et al., 2013).

Agyeman, J. (2013). Introducing Just Sus-tainabilities: Policy, Plannig, and Practice. Ney York: Zed Books. 
Arefi, M. (2011). Design of resilient cities, reflections from a studio. In L.-S. Tidib (Ed.), Companion to urban desgn (pp. 674-685). Abingdon: Routledge.

Biggs, R., Schüter, M., \& Schoon, M. L. (2015). Principles for building resilience: Sustaining ecosystem services in social-ecological systems. Cambridge: Cambridge University Press.

Campanella, T. (2006). Urban Resilience and the Recovery of New Orleans. Journal of the American Planning Association, 72(2), $141-146$.

Chelleri, L., \& Olazabal, M. (2012). Multidisciplinary perspectives on urban resilience: a workshop report. (1st ed.). Bilbao: Basque Centre for climate change.

Cutter, S. (1995). Race, class, and environmental justice. Progress in Human Geography. In P. Robbins, Political Ecology (págs. 107-118).

Eraydin, A. (2013). "Resilience Thinking" for Planning. In Eraydin \& A., Tasan-Kok, T. (Eds). Resilience Thinking in Urban Planning.

Folke, C., S. R. Carpenter, B. Walker, M. Scheffer, T. Chapin, and J. Rockström. (2010). Resilience thinking: integrating resilience, adaptability and transformability. Ecology and Society 15(4): 20. Retrieved from http://www.ecologyandsociety.org/vol15/iss4/art20/.

Gobierno de la Ciudad de México. (2014). Programa de Accion Climatica de la Cidad de México 2014-2020. Ciudad de México: Gobierno de la Ciudad de México.

Gunderson, L., Kinzig, A., Quinlan, A., \& Walker, B. (2011). Resilience: leading transformational Change. Ecology and society, 16(2).

Hearn, B. (2008). Community resilience: A social justice perspective. Florida: Community and Regional Resilience Initiative.

Holling, C. (1973). Resilience and stability of ecological systems. Annual Review of Ecology and Systematics, 4, 1-23.

ICLEI. (2012). Resilient Cities 2012: Congress Report. Bonn. Germany. ICLEI.

INEGI. (2010). Usos del suelo y vegetación del Distrito Federal. Aguascalientes: INEGI.

Jabareen, Y. (2012). Planning the resilient city: Concepts and strategies for coping with climate change and envirenmental risk. In Cities. Retrieved from http://dx.doi.org.ezp.sub.su.se/10.1016/j.cities.2012.05.004

Lampis, A. (2015). Resiliencie \& cities. Critical thoughts on an emerging paradigm [Entrada en blog]. UGEC VIEWPOINTS. Retrieved from (https://ugecviewpoints.wordpress.com/2015/10/08/resilience-cities-criticalthoughts-on-an-emerging-paradigm/)

López, F. M. (2006). Niveles de dotación de agua y drenaje en la Zona Metropolitana de la Ciudad de México. En A. G. Aguilar (Ed.), Las grandes aglomeraciones y su periferia regional (pp. 143-179). México: Porrúa, UNAM.

McPhearson, T. (2014, June 08). The nature of cities. The Rise of Resilience: Linking Resilience and Sustainability in City Planning Retrieved from http://www.thenatureofcities.com/2014/06/08/the-rise-of-resilience-linkingresilience-and-sustainability-in-city-planning/

Mitchell, J. (Ed.). (1999). Crucibles of Hazard: Mega-Cities and Disasters in Transition. Ney York: United Nations University Press. 
Molina, M., Belausteguigoiti, J. Velasco, G., Becerra, L., \& Carreras, I. (2013). Propuestas estratégicas para el desarrollo sustentable de la Megalópolis del centro de México. México D.F.: Centro Mario Molina para Estudios Estratégicos.

Heynen, N., M, Kaika., \& Swyngedouw E. (2006). In the nature of cities: urban political ecology and the politics of urban metabolism. London and New York: Routledge Taylor \& Francis Group.

Olsson, P., Gunderston, S. R., Carpenter, P., Ryan, L., Lebel, C., Kolke, C., \& Holling, S. (2006). Shooting the rapids:navigating transitions to adaptive governance of socioecologycal systems. Ecology and Society, 11(1), 18. Retrieved from http://www.ecologyandsociety.org/vol9/iss4/art2/

Quintero, L. (2016). CDMX estrenará plan de resiliencia en septiembre. El economista, p. 12.

Resilience Alliance. (2007). Urban Resilience Research Prospectus: A Resilience Alliance Initiative for Transition Urban System Towards Sustainable Futures. Resilience Alliance.

Robins, P. (2012). Political Ecology. New York: Wiley-Blackwell.

Rosales, N. (2013). "Nuevos desafíos de la planificación urbana: pautas para la instrumentación de los principios de sostenibilidad y su aplicación al caso de la Ciudad de México". Madird: Instituto Universitario de Ciencias Ambientales, Universidad Complutense de Madrid.

Rosales, Natalie (2017). "How can an Ecological Perspective be used to Enrich Cities Planning and Management?", Urbe - Revista Brasileira de Gestão Urbana. 9(2), 314-326

SEMARNAT. (2010). Balance del agua.

http://app1.semarnat.gob.mx/dgeia/informe_resumen/07_agua/cap7.html.

SENER. (2009). Prospectiva del Consumo ener-gético 2009. Mexico: Retrieved from: http://sie.energia.gob.mx/. The Bartlett Development Planning Unit. (12 March 2016). Environment, justice, urbanization and resilience. [Blog]. The Bartlett Development Planning Unit. Retrieved: (https://www.ucl.ac.uk/bartlett/development/research/researchclusters/environmental-justice-urbanisation-resilience)

Tudela, F. (1991). El laberinto de la complejidad. Hacia un enfoque sistemico del ambiente y la gestión de los servicios en América Latina. Ciudad de México: El Colegio de Mexico.

UN HABITAT. (2016). Resilience. Retrieved from http://es.unhabitat.org/temasurbanos/resiliencia/)

Walker, B., \& Salt, D. (2006). Resilience thinking: Sustaining Ecosystems an People in a Changing World. Washington: Island Press.

Wilbanks, T. J. (2008). Enhancing the Resilience of Communities to Natural and Other Hazards: What We Know and What We Can Do. Natural Hazards Observer. 32(4), 10-11

World Watch Institute. (2007). La situación del mundo 2007. Nuestro futuro urbano. Informe anual sobre el progreso hacia una sociedad sostenible. Barcelona: Ed. Icaria. 